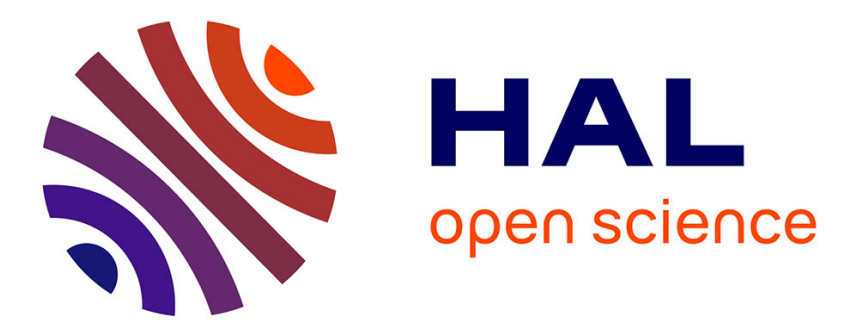

\title{
Impact of cerium and lanthanum on the photo-darkening and photo-bleaching mechanisms in thulium-doped fibre
} Jean-François Lupi, Manuel Vermillac, Wilfried Blanc, Franck Mady, Mourad Benabdesselam, Bernard Dussardier, Daniel R. Neuville

\section{- To cite this version:}

Jean-François Lupi, Manuel Vermillac, Wilfried Blanc, Franck Mady, Mourad Benabdesselam, et al.. Impact of cerium and lanthanum on the photo-darkening and photo-bleaching mechanisms in thuliumdoped fibre. Optical Materials, 2017, 72, pp.106-114. 10.1016/j.optmat.2017.04.066 . hal-01598970

\section{HAL Id: hal-01598970 \\ https://hal.science/hal-01598970}

Submitted on 12 Nov 2017

HAL is a multi-disciplinary open access archive for the deposit and dissemination of scientific research documents, whether they are published or not. The documents may come from teaching and research institutions in France or abroad, or from public or private research centers.
L'archive ouverte pluridisciplinaire HAL, est destinée au dépôt et à la diffusion de documents scientifiques de niveau recherche, publiés ou non, émanant des établissements d'enseignement et de recherche français ou étrangers, des laboratoires publics ou privés. 


\title{
Impact of cerium and lanthanum on the photo-darkening and photo- bleaching mechanisms in thulium-doped fibre
}

\author{
Jean-François Lupi ${ }^{\text {a }}$, Manuel Vermillac ${ }^{\text {a }}$, Wilfried Blanc ${ }^{\text {a, }}$, Franck Mady ${ }^{\text {a }}$, \\ Mourad Benabdesselam ${ }^{\mathrm{a}}$, Bernard Dussardier ${ }^{\mathrm{a}}$, Daniel R. Neuville ${ }^{\mathrm{b}}$ \\ a Université Côte d'Azur, CNRS, INФNI, UMR7010, Parc Valrose, 06108 Nice, Cedex 2, France \\ b Équipe des Géomatériaux, IPGP, COMUE Sorbonne Paris-Cité, CNRS UMR 7154, 1 Rue Jussieu, 75005 Paris, France
}

Keywords:

Optical fibre

Thulium

Photo-darkening

Silica

\begin{abstract}
A B S T R A C T
Photo-darkening prevents developing of new applications of rare-earth doped silica fibre lasers or amplifiers operating at wavelengths shorter than $1 \mu \mathrm{m}$ or at any wavelength at high power. The photodarkening is characterized by a decrease of the laser intensity during amplification. In this article, we are interested in $\mathrm{Tm}$-doped fibres. This ion offers many potential optical transitions spanning from 0.45 to $1.9 \mu \mathrm{m}$. Several interesting transitions can be excited via up-conversion, using one pump around $1 \mu \mathrm{m}$. However, this scheme induces a particularly fast and intense photo-darkening, enough to prevent amplification in the short wavelengths region $(0.45-0.9 \mu \mathrm{m})$. To mitigate this effect, we co-dope the fibres with cerium or lanthanum ions. By characterizing the steady state values of photo-darkening and its characteristic times, we demonstrate the beneficial role of $\mathrm{Ce}$ and $\mathrm{La}$ on the bleaching mechanisms.
\end{abstract}

\section{Introduction}

Silica as a glass host for rare-earth (RE) doped fibre lasers and amplifiers offers the best performances in terms of efficiency, power, reliability and cost effectiveness. It is indeed chemically stable, mechanically robust and its optical transparency is high in the visible and the near-infra-red (NIR) range up to $2 \mu \mathrm{m}$. Then, silica is the main glass used, for example, in high power fibre lasers [1]. In the case of $Y b$-doped fibre, this technology reaches kilowatt level in single mode and continuous wave regime. Presently, one of the main issues related to the output power is related to the photodarkening mechanism. It is characterized by the presence of a broad absorption band in the visible and NIR. It causes the decreasing of the laser power versus time. This induced loss has a significant impact on the threshold and the laser slope efficiency [2]. In addition, photo-darkening is suspected also to trigger mode instability, leading to a degradation of the $M$ factor of these lasers [3-6].

For the development of fibre lasers at wavelengths shorter than $1 \mu \mathrm{m}$, thulium $\left(\mathrm{Tm}^{3+}\right)$ is particularly interesting because it offers many potential optical transitions spanning from 0.45 to $1.9 \mu \mathrm{m}$.

\footnotetext{
* Corresponding author

E-mail address: wilfried.blanc@unice.fr (W. Blanc).
}

Except for the conventional pumping scheme at $0.79 \mu \mathrm{m}$ which provides efficient amplification around $1.9 \mu \mathrm{m}$ through a downconversion energy transfer process [7], none of the other transitions are exploited in silica. An interesting up-conversion pumping scheme using a pump source at $1.07 \mu \mathrm{m}$ provides up to seven laser emissions (spanning from 0.45 to $1.9 \mu \mathrm{m}$ ) that were implemented in ZBLAN fibres [8]. If one applies this scheme to a Tm-doped silica fibre, two phenomena will hamper amplification: fluorescence quenching by non-radiative decay and transparency degradation by photo-darkening $[9,10]$. The high phonon-energy of silica glass (as compared with fluorides) induces fast non-radiative decays from most energy levels of thulium, causing a strong reduction of their effective lifetimes and hence the reachable population inversion, even under high pumping. In Tm-doped silica, the non-radiative decay from the ${ }^{3} \mathrm{H}_{4}$ excited level may be mitigated by high $\mathrm{Al}$ codoping, promoting the amplification of the $0.8 \mu \mathrm{m}$ and $1.47 \mu \mathrm{m}$ emission bands as well as up-conversion to higher energy levels (see Fig. 1 right) [9,11,12]. Because the seeked applications necessitate high concentrations of aluminium and thulium, strong photo-darkening is observed $[10,13]$. Besides, pumping of RE-doped optical fibres may cause the degradation of the transparency of both silica and fluoride glasses, especially when they are heavily doped with RE ions [10,13-17]. In the case of thulium-doped silica fibre pumped at $1.07 \mu \mathrm{m}$, photo-darkening (or photo-induced 

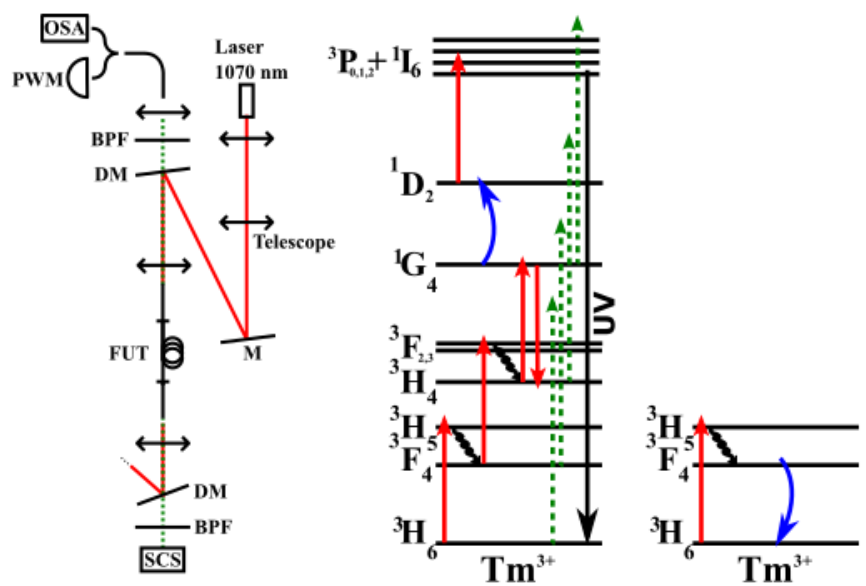

Fig. 1. Left: Experimental setup for PIA measurement. M: dielectric mirror, FUT: fiber under test, BPF: band pass filter, DM: dichroic mirror, OSA: optical spectrum analyser, SCS: supercontinuum source, PWM: power meter. Right: Energy level diagram of $\mathrm{Tm}^{3+}$ : red: pump induced transitions, blue: energy transfer, green: $0.55 \mu \mathrm{m}$ probe. (For interpretation of the references to colour in this figure legend, the reader is referred to the web version of this article.)

attenuation, $P I A$ ) is particularly fast and intense, enough to prevent amplification in the extended-visible region $(0.45-0.9 \mu \mathrm{m})$ [10]. The beneficial role of co-doping with cerium or lanthanum ions to mitigate the steady states of photo-darkening has been reported previously [18]. The aim of this article is to study both the steady state of photo-darkening and its characteristic time to discuss the role of $\mathrm{Ce}$ and $\mathrm{La}$ on the generation and bleaching mechanisms.

\section{Samples preparation}

Preforms were fabricated by the conventional Modified Chemical Vapor Deposition (MVCD) technique [19] and the so-called solution doping technique [20] was applied to incorporate aluminium $(A l)$, thulium $(T m)$, cerium $(C e)$ and lanthanum $(L a)$ ions. To fabricate a preform, a porous silica layer was deposited inside substrate silica tube. After soaking of the layer with ionic solutions of chloride salts, the solvent was dried and the core layer was sintered down to a dense glass layer. Then the tube was collapsed into a solid rod, referred to as preform, at an elevated temperature higher than $1800^{\circ} \mathrm{C}$. Preforms were stretched into $125 \mu \mathrm{m}$ fibres using a drawing tower at temperatures higher than $2000^{\circ} \mathrm{C}$ under normal conditions. Three series of samples were prepared with various concentrations of thulium, lanthanum and cerium ions. The concentrations of $\mathrm{Al}, \mathrm{Tm}, \mathrm{Ce}$ and $\mathrm{La}$ were measured by EPMA (Electron Probe Micro-Analysis) in the fibres. All the concentrations are given in atomic ppm and reported in Table 1. In all samples, the concentration of aluminum remained almost constant, typically around $8000 \mathrm{ppm}$. In the $\mathrm{Tm}$ series, the concentration of thulium spans from 0 to $600 \mathrm{ppm}$. In the $L a$ series, the concentration of lanthanum varies from 350 to $7000 \mathrm{ppm}$ whereas the concentrations of thulium remains almost constant $(190 \pm 30 \mathrm{ppm})$. In the Ce series, the concentration of cerium varies from 0 to $1300 \mathrm{ppm}$ whereas the concentration of thulium remains almost constant $(260 \pm 40 \mathrm{ppm})$.

Table 1

Concentrations of all elements incl. oxygen (ppm.at).

\begin{tabular}{lllll}
\hline Series & {$[\mathrm{Tm}]$} & {$[\mathrm{La}]$} & {$[\mathrm{Ce}]$} & {$[\mathrm{Al}]$} \\
\hline$T m$ & $0-600$ & - & - & $\sim 8000$ \\
$L a$ & $190 \pm 30$ & $0-7000$ & - & $\sim 8000$ \\
$\mathrm{Ce}$ & $260 \pm 40$ & - & $0-1300$ & $\sim 8000$ \\
\hline
\end{tabular}

\section{Experimental setups}

Photo-darkening, fluorescence lifetime and fluorescence measurements were performed in this study.

\subsection{Photo-darkening}

Fig. 1 describes the experimental setup used to measure the PIA. The pump laser at $1.07 \mu \mathrm{m}$ is a continuous wave $Y b$-doped fibre laser (Keopsys, KPS-CUS-OEM-1064). It was coupled into a commercial passive fibre (Corning, HI-1060, referred to as "input fibre") through a telescope, a high reflection dielectric mirror, a dichroic mirror and an aspherical lens. The dichroic mirror is highly reflective at $1.07 \mu \mathrm{m}$ and transparent from 0.55 to $1.0 \mu \mathrm{m}$. The input fibre end was cleaved at right angle. The fibre under test (FUT) samples were spliced to the input fibre. The typical length of samples was about $2 \mathrm{~cm}$, short enough to neglect the pump depletion (loss $<1 d B$ at $1.18 \mu \mathrm{m}$ ). Another passive HI-1060 fibre was spliced at the other end of the FUT. A super continuum source (SCS, Leukos SM-30) was coupled into the passive fibre in the counter-propagative direction relative to the pump beam, using two metallic mirrors (not represented) and an aspherical lens. The remaining pump was rejected by a second dichroic mirror, so that the SCS was protected against laser damage. Two band pass filters at $0.55 \mu \mathrm{m}$ with a $2-\mathrm{nm}$ bandwidth were placed before and after the FUT. Their extinction ratio is higher than $40 \mathrm{~dB}$. Next, the green beam is called the probe.

The injected pump was measured from the end of the input fibre by a power meter before the splicing of the FUT. The time-resolved PIA measurement was recorded at $0.55 \mu \mathrm{m}$ while pumping at $1.07 \mu \mathrm{m}$. This probe wavelength was selected because the PIA is strong whereas there is no absorption band of $\mathrm{Tm}^{3+}$ ions at $0.55 \mu \mathrm{m}$. The band pass filters were placed, the SCS was turned on, and the PWM (Si photo-diode) was used to continuously measure the transmitted probe while pumping. The recording was continued after the laser was turned off, in order to measure bleaching dynamics caused by the probe.

The probe power can affect the measurements. For example, Fig. 2 shows steady state values of photo-induced attenuation for the $\mathrm{Tm}$-doped sample containing the highest concentration of $\mathrm{Ce}$ $(1300 \mathrm{ppm})$ as a function of the probe power. The steady state values of the PIA (PIA $\left.A_{s t}\right)$ span from $44 \mathrm{~dB} / \mathrm{m}$ to $90 \mathrm{~dB} / \mathrm{m}$ when the probe power increases from $2 n W$ up to $25 \mu W$. The same trend was observed in the $L a$ series. To minimize the effect of the probe in the case of $\mathrm{Ce}$ or La doped samples, it is necessary to use a probe power lower than $\sim \mu \mathrm{W}$. Therefore photo darkening

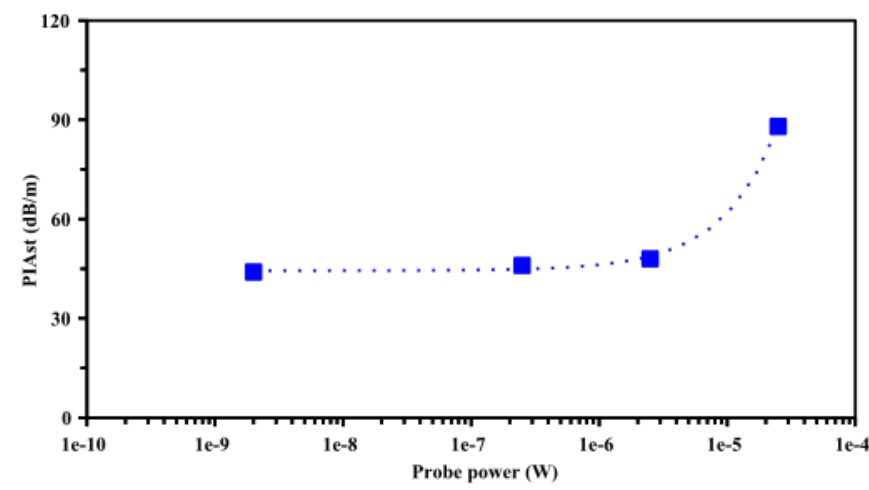

Fig. 2. $P I A_{s t}$ values obtained for various probe powers spanning from $2 n W$ to $25 \mu W$, for pump power of $1 \mathrm{~W}$ measured in the $1300 \mathrm{ppm}$ cerium-doped sample. Dot: experimental values, dotted line: linear fitting. 
measurements should be performed at these low probe power in order to quantify only the effect of the pump and rare-earth ions concentrations. In the case of singly Tm-doped samples, we have checked that a higher probe power $(25 \mu \mathrm{W})$ does not disturb the measurements.

\subsection{Fluorescence spectra}

The experimental setup used to measure the fluorescence spectra of $\mathrm{Tm}^{3+}$ is described in Fig. 1. The pump wavelength was $1.07 \mu \mathrm{m}$. For these measurements, the SCS and the filter were not used. The contra-propagative fluorescence was collected and measured by an optical Fourier transform analyser (Thorlabs OSA201C). The spectra were acquired from $400 \mathrm{~nm}$ to $1 \mu \mathrm{m}$ with different pump powers. All spectra present a parasitic peak at $632.8 \mathrm{~nm}$ which is due to the intrinsic $\mathrm{He}-\mathrm{Ne}$ reference inside the device. When the pump power is lower than $250 \mathrm{~mW}$, photodarkening can be neglected for few minutes. When the pump power is higher than $500 \mathrm{~mW}$, the intensity of the emission spectrum is impacted by the photo-darkening particularly in the shortwavelengths domain.

\subsection{Fluorescence lifetimes}

Fig. 3 describes the experimental setup used to measure the fluorescence lifetime of the ${ }^{3} \mathrm{H}_{4}$ level of $\mathrm{Tm}^{3+}$. The pump laser was a fibre coupled laser-diode emitting at $785 \mathrm{~nm}$. A 50/50 coupler was used to collect the backward fluorescence. The fibre under test was spliced on one of the coupler arms. Both ends are immersed in index liquid to prevent any reflection of parasitic light. The contrapropagative fluorescence was collected, then filtered by a spectrometer tuned to $810 \mathrm{~nm}$ (resolution $\sim 0.1 \mathrm{~nm}$ ). The output light was detected by an amplified avalanche silicon photodiode (APD, EG\&G SPCM AQR-14-FC) operated in the photon-counting mode. The TTL electrical pulses from the APD were counted by a Stanford SR400 photon counter synchronized by the laser diode modulation signal. Decay curves were registered using a time-gate scanning across one pump modulation period. In order to minimize errors (laser fluctuations,...) and increase the $\mathrm{S} / \mathrm{N}$ ratio, the signal was normalized in real time by the signal from a fixed time-gate integrating the signal over a full $1-m s$ modulation period, and each data point was averaged 5000 times. A decay curve contains typically 500 data points.

\section{Rate equation model}

In this section, we present the model used to discuss the darkening and the bleaching phenomena. It is well-known that light can be absorbed by precursors present in the glass, leading to the formation of color-centres absorbing in the visible. In silica, many different color-centres have been identified. For the sake of simplicity in this model, we consider the formation of one generic

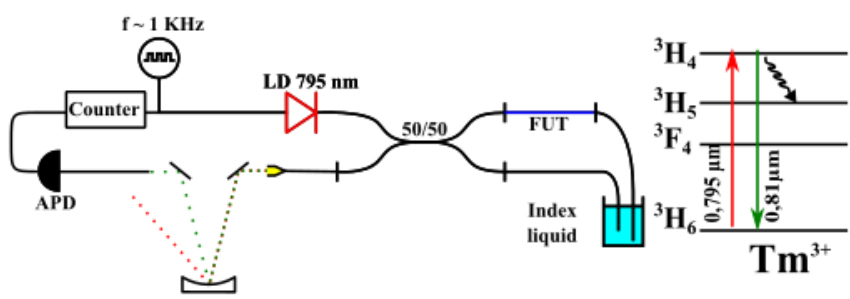

Fig. 3. Experimental setup used to measure the fluorescence lifetime of the ${ }^{3} \mathrm{H}_{4}$ level of $\mathrm{Tm}^{3+}$. APD: avalanche photo-diode. FUT: fibre under test. color-centre which can be photo-bleached. In this case, the normalized density $n$ of color-centres is ruled by the generation $(g)$ and the bleaching $(b)$ rates. The time derivative of the number of color-centres $\dot{n}$ has two contributions: (i) g. $(1-n)$ which is the generation term requiring a exhaustible source, (ii) $-b . n$ which is the bleaching term requiring a color-centre to bleach. These considerations lead to the differential equation (1).

$\dot{n}=g .(1-n)-b . n$

According to the Beer-Lambert law, the generation of one colorcentre, characterized by the absorption coefficient $\alpha_{c c}$, leads to the photo-induced absorption $P I A=\alpha_{c c} \cdot n$ (in $d B / m$ ). The resolution of equation (1) gives the temporal form of $P I A(t)$ :

$P I A(t)=\alpha_{c c} \cdot \frac{g}{g+b}\left(1-e^{-(g+b) \cdot t}\right)$

Equation (2) exhibits two parameters: $P I A_{s t}=\alpha_{c c} \cdot \frac{g}{g+b}$ and $\tau_{1 / e}=$ $\frac{1}{g+b}$ which are the steady state value of PIA and the characteristic time, respectively. Both parameters can be determined experimentally. Reversed relations are: $\alpha_{c c} \cdot g=\frac{P I A_{s t}}{\tau_{1 / e}}$ and $(g+b)=\frac{1}{\tau_{1 / e}}$. As the value of $\alpha_{c c}$ is unknown, $g$ and $b$ cannot be determined separately.

The measurements of PIA $A_{s t}$ and $\tau_{1 / e}$ allow to discuss on the increase or the decrease of the photo-darkening and the photobleaching rates. Indeed, when $P I A_{s t}$ increases and $\tau_{1 / e}$ decreases, the phenomenon is ruled by the increasing of $g$. When both PIA $A_{s t}$ and $\tau_{1 / e}$ increase, the phenomenon is ruled by the decreasing of $b$. When both $P I A_{s t}$ and $\tau_{1 / e}$ decrease, the phenomenon is ruled by the increasing of $b$. Finally, when PIA $A_{s t}$ decreases and $\tau_{1 / e}$ increases, the phenomenon is ruled by the decreasing of $g$. Table 2 synthesises the link between the measured parameters $\left(P I A_{s t}\right.$ and $\left.\tau_{1 / e}\right)$ rates of photo-darkening and photo-bleaching.

This model is based on the assumption that only one kind of color-centre is implied. To discuss this statement, Fig. 4 shows one typical decay curve of the PIA fitted with a single, a double and a stretched exponential. The experimental curve was measured in an Al-Tm doped sample pumped at $1 \mathrm{~W}$ and with a probe at $550 \mathrm{~nm}$ (power: $25 \mu W$ ).

The best curve fittings correspond to double and stretched exponential cases. Stretched exponentials are commonly used to describe non-exponential decay curve, but there is no easy interpretation of the stretch parameter. The two-exponentials fitting can be explained by the formation of two color-centres. However, the experimental values of interest $\left(P I A_{s t}\right.$ and $\left.\tau_{1 / e}\right)$ are well fitted even with the single exponential decay curve. The single exponential curve fails to fit the intermediate part, which is out of interest in this study. For these reasons, we consider here the formation of one generic color-centre.

\section{Results}

\subsection{Effect of thulium concentration on the photo-darkening}

In this subsection, we consider the Tm samples series. The effect

Table 2

Effects of the increase and decrease of $P I A_{s t}$ and $\tau_{1 / e}$ on the generation and bleaching rates.

\begin{tabular}{lllll}
\hline$P I A_{\text {st }}$ & $\uparrow$ & $\uparrow$ & $\downarrow$ & $\downarrow$ \\
$\tau_{1 / e}$ & $\downarrow$ & $\uparrow$ & $\downarrow$ & $\uparrow$ \\
\hline Ruling rate & $g \uparrow$ & $b \downarrow$ & $b \uparrow$ & $g \downarrow$ \\
\hline
\end{tabular}




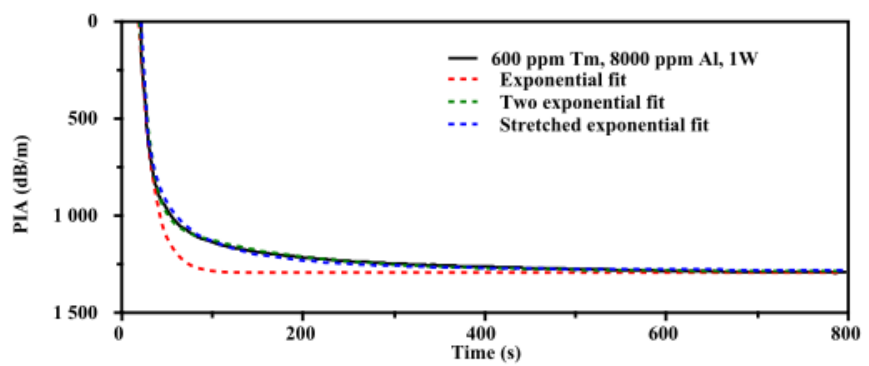

Fig. 4. Time resolved PIA for a sample containing $600 \mathrm{ppm} \mathrm{Tm}$ and $8000 \mathrm{ppm} \mathrm{Al}$ and three fitting curves. Pump power: $1 \mathrm{~W}$, probe power: $25 \mu \mathrm{W}$.

of thulium concentration on the PIA $A_{s t}$ and the characteristic time $\tau_{1 / e}$ is reported in Fig. 5. As reported previously, when Tm concentration increases from 0 to $600 \mathrm{ppm}, P I A_{s t}$ increases from 0 to $1300 \mathrm{~dB} / \mathrm{m}$. The data can be fitted with a power law, with an exponent equals to $1 / 2$ for the dependence on $\mathrm{Tm}$ concentration (dotted line in the inset of Fig. 5) [18]. The same trend was observed in $\mathrm{Yb}$-doped silica with varying $\mathrm{Tm}$ concentration and probe light at $633 \mathrm{~nm}$ [13]. The characteristic time decreases from 115 to $6 s$ when $\mathrm{Tm}$ concentration increases from 160 to $600 \mathrm{ppm}$. For this range of $\mathrm{Tm}$ concentration, the characteristic time can be fitted with an exponential law (dotted line in Fig. 5). At concentrations lower than $150 \mathrm{ppm}$, it is expected that $\tau_{1 / e}$ behaviour deviates from this exponential law. Indeed, when $\mathrm{Tm}$ concentration tends to $0, P I A_{s t}$ tends to 0 and $\tau_{1 / e}$ tends to infinity. According to the data reported in Fig. 5, in the $200-600 \mathrm{ppm}$ range, $\tau_{1 / e}$ is very sensitive to the $\mathrm{Tm}$ concentration as it varies by a factor 30 while the $P I A_{s t}$ varies by a factor 2 only.

The inset of Fig. 6 reports the PIA $A_{s t}$ values for the sample doped with the highest content of $T m$ and for pump power $(P)$ varying from $300 \mathrm{~mW}$ to $4 \mathrm{~W}$. PIA $A_{s t}$ values increase with the pump power. These data can be fitted with this law: PIAst $=P I A_{s t}^{\text {sat } \frac{A . P}{1+A . P}}$ where $A=$ $0.86 W^{-1}$ and $P I A_{s t}^{s a t}=2700 \mathrm{~dB} / \mathrm{m}$. The variation of the characteristic time $\tau_{1 / e}$ versus $P$ is reported in Fig. 6 . These values are fitted with a power law whose exponent is -5.29 and -1.72 when pump power is lower or higher than $0.7 \mathrm{~W}$, respectively. In the case of $\mathrm{Yb}$-doped silica fibres, a power-law dependence was reported and the exponent was associated to the number of photons implied in the photo-darkening process [21]. Based on this consideration, at low pump power, the phenomenon would be ruled by the absorption of 5 or 6 photons while at higher pump power only 1 or 2 photons would be involved. These two processes can be tentatively

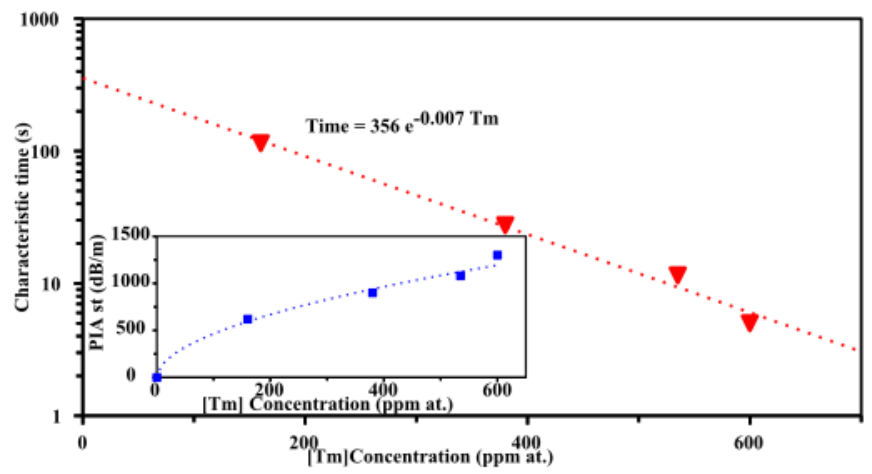

Fig. 5. Characteristic time for various thulium concentrations, from 0 to $600 \mathrm{ppm}$ and $8000 \mathrm{ppm} \mathrm{Al}$. Measured at $1 \mathrm{~W}$ pump power and $25 \mu \mathrm{W}$ of $550 \mathrm{~nm}$ probe. Dot: experimental data, dotted lines: exponential fitting. Inset: $P I A_{\text {st }}$ corresponding, Dot: experimental data, dotted line: square-root fitting.

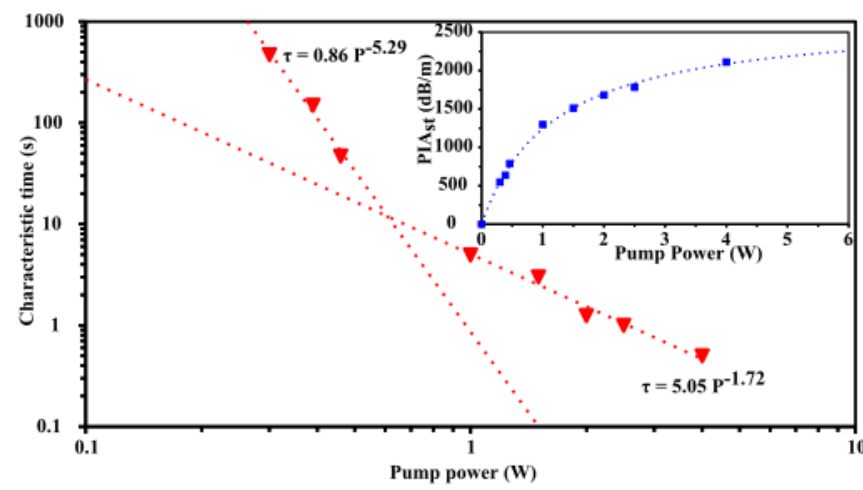

Fig. 6. Characteristic times for the $600 \mathrm{ppm} \mathrm{Tm}$ and $8000 \mathrm{ppm}$ Al sample, for pump powers spanning from $300 \mathrm{~mW}$ to $4 \mathrm{~W}$, measured at $550 \mathrm{~nm}$. Dot: experimental data, dotted lines: power law fittings. Inset: PIA $A_{\text {st }}$ values for the same measurements. Dot: experimental data, dotted lines: fitting with saturate linear.

interpreted as follows.

For the sample with the highest $\mathrm{Tm}$ concentration, the emission spectra were measured under $1.07 \mu \mathrm{m}$ pumping scheme with pump power varying between 0 and $4 \mathrm{~W}$. A characteristic emission spectrum is reported in Fig. 7 and corresponds to the pump power of $250 \mathrm{~mW}$. For higher pump power, the emission spectra in the visible domain are difficult to measure due to the photo-darkening effect. The emission spectrum exhibits three emission bands at 470 , 530 and $650 \mathrm{~nm}$. These emission bands are attributed to $\mathrm{Tm}^{3+}$ ions. Blue and red emissions can be attributed to de-excitations from the ${ }^{1} G_{4}$ manifold. This level is populated through up-conversion mechanism (3-photon absorption) described in Fig. 1. The green emission band is emitted from energy levels higher than the ${ }^{1} G_{4}$. The ${ }^{1} D_{2}$ level can be populated through energy transfer between two $\mathrm{Tm}^{3+}$ ions: a $\mathrm{Tm}^{3+}$ ion absorbs a pump photon to reach the ${ }^{3} \mathrm{H}_{5}$ level and decays non-radiatively to the ${ }^{3} F_{4}$ level. Then, the energy transfer $\left({ }^{3} F_{4},{ }^{1} G_{4}\right) \rightarrow\left({ }^{3} H_{6},{ }^{1} D_{2}\right)$ takes place as already observed in fluoride glass [22]. From the ${ }^{1} D_{2}$ level, the $\mathrm{Tm}^{3+}$ ion can absorb another pump photon to reach the ${ }^{3} P_{0,1,2}$ and ${ }^{1} I_{6}$ levels. According to these processes, reported in Fig. 1, the absorption of 5 pump photons leads to the emission of UV light. These UV photons are expected to be involved in the photo-darkening process because they can ionize precursor defects such as the $A l-E^{\prime}$ and $N B O H C$ centres [14,23-25]. In this case, electrons are released in the conduction band and holes in the valence band. These charges can then recombine on traps to form color-centres: the $\mathrm{AlOHC}$ in the case of

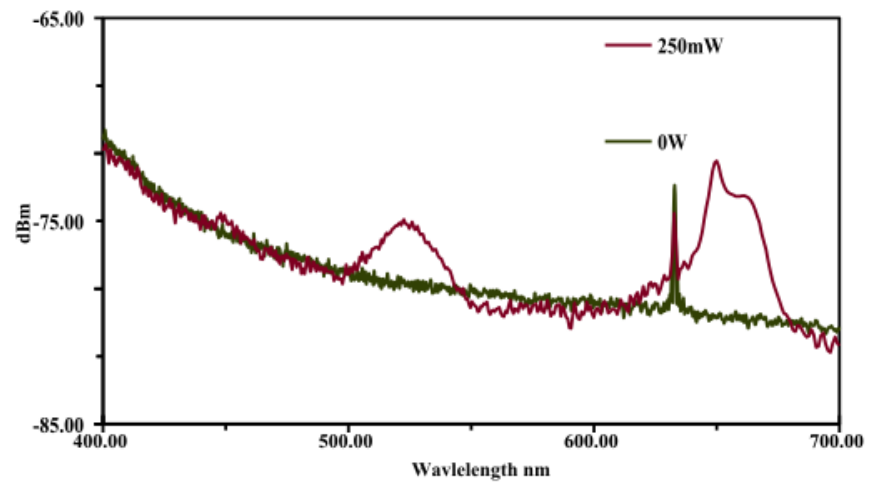

Fig. 7. Visible-NIR fluorescence under $1.07 \mu \mathrm{m}$ pumping, for the sample doped with $600 \mathrm{ppm} \mathrm{Tm}$ and $8000 \mathrm{ppm}$ Al. Res: $1 \mathrm{~nm}$, peak at $632.8 \mathrm{~mm}$ : artefact from OSA. 


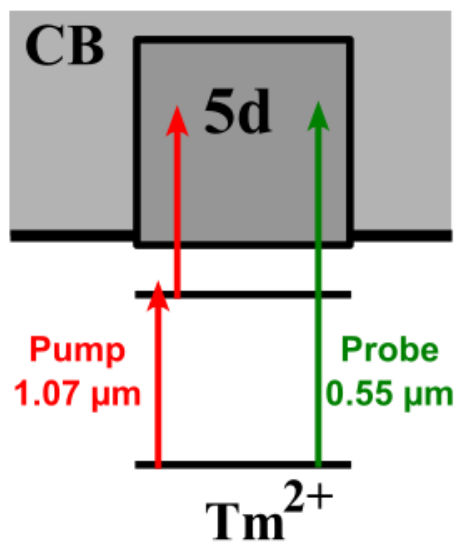

Fig. 8. Schematic representation of bleaching mechanisms by $\mathrm{Tm}^{2+}$ ion. Red: pump photon, green: probe. CB: Conduction band. (For interpretation of the references to colour in this figure legend, the reader is referred to the web version of this article.)

hole, or, in the case of electron, on a $\mathrm{Tm}^{3+}$ to form a $\mathrm{Tm}^{2+}$. AlOHC and $\mathrm{Tm}^{2+}$ absorb in the visible [26]. As a conclusion, at low pump power, the variation of the characteristic time is associated to the generation of color-centres due to the UV emission induced by the 5-photons absorption mechanism of $\mathrm{Tm}^{3+}$ (see Fig. 8).

For pump power higher than $0.7 \mathrm{~W}$, thulium ions undergo a similar effect as the induced transparency. Indeed, there is a competition between the absorption of pump photon on the ${ }^{3} \mathrm{H}_{4} \rightarrow{ }^{1} \mathrm{G}_{4}$ transition and the stimulated emission of the opposite transition. Then, at high pump power, populations of the ${ }^{3} \mathrm{H}_{4}$ and ${ }^{1} G_{4}$ levels are saturated and the ratio of these populations is the ratio of the absorption cross-sections and associated emission cross-sections. If these populations are saturated, it can be deduced that the pump has no more interactions with $\mathrm{Tm}^{3+}$ ions and therefore the generation of color-centres saturates.

For pump power higher than $1 \mathrm{~W}$, PIA st starts to saturate and the characteristic time evolves differently as the exponent of the power law is between 1 and 2. The ground level of the $\mathrm{Tm}^{2+}$ ions, initially present in the glass or induced by UV emission, is located close to the bottom of the conduction band $(\sim 1.9 \mathrm{eV})[27,28]$. Moreover, the $4 f-4 f$ transition of $\mathrm{Tm}^{2+}$ occurs at $\sim 1 \mathrm{eV}[26,29,30]$. Then, only one probe photon $(\sim 2.25 \mathrm{eV})$ or two pump photons ( $\sim 1.16 \mathrm{eV}$ each) suffice to ionize $\mathrm{Tm}^{2+}$ ions (see Fig. 8). Once the $\mathrm{Tm}^{2+}$ ion is ionized, it becomes a $\mathrm{Tm}^{3+}$ and an electron is released in the conduction band. This electron can recombine on a $\mathrm{Tm}^{3+}$ ion, a trap defect or return to its ionized precursor. This last case allows to bleach the degradation.

\subsection{Effect of cerium and lanthanum concentrations on the photo- darkening under pumping}

The characteristic times and the PIA $A_{\text {st }}$ values for different concentrations of $C e$ and $L a$ are reported in Figs. 9 and 10, respectively. In both cases, as the rare-earth ion concentration increases, PIAst and characteristic time decrease. Ce reduces PIA $A_{s t}$ from 720 to $42 \mathrm{~dB} / \mathrm{m}$ and the characteristic time from 150 to $15 \mathrm{~s}$. La reduces $P I A_{s t}$ from 675 to $250 \mathrm{~dB} / \mathrm{m}$ and the characteristic times from 250 to $6 \mathrm{~s}$.

The characteristic time and PIA $A_{s t}$ values have been measured for the sample with the highest concentration of $\mathrm{Ce}$ for different pump powers. The data are reported in Fig. 11. As already observed in the case without $\mathrm{Ce}$ (cf Fig. 6), the $P I A_{s t}$ increases with the pump power. Data were fitted with the law $P I A_{\text {st }}=P I A_{\text {st }}^{\text {sat }} \frac{A P}{1+A P}$ where

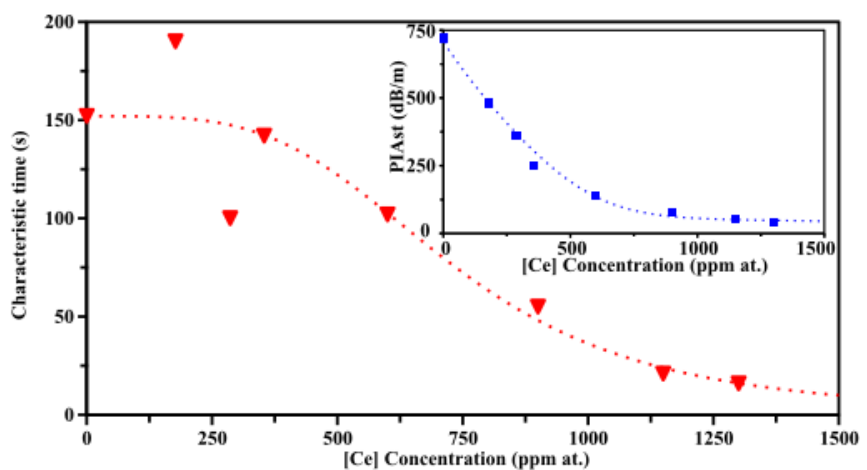

Fig. 9. Characteristic times and $P I A$ steady state values (inset) as a function of cerium concentration. Pump power: $1 \mathrm{~W}$, probe power: $2 \mathrm{nW}$. Dot: experimental values, dotted lines: fittings explained in the text.

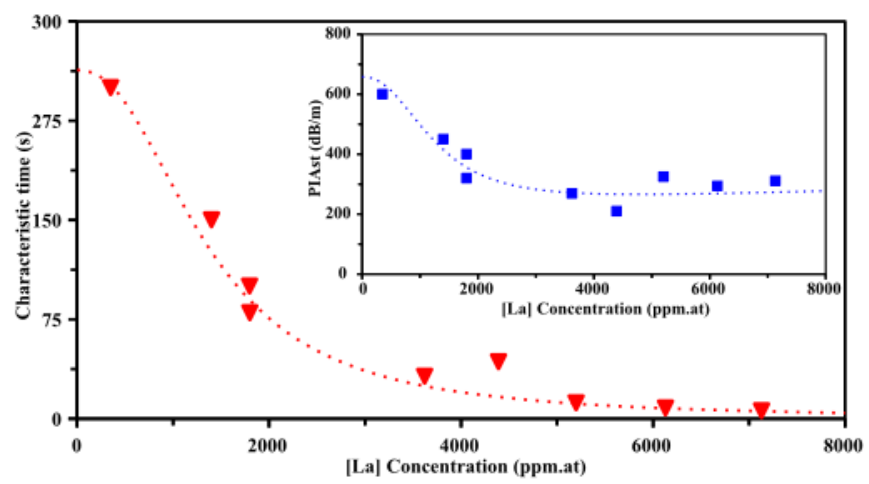

Fig. 10. Characteristic times and PIA steady state values (inset). Pump power: $1 \mathrm{~W}$ probe power: $2 \mathrm{nW}$. Dot: experimental values, dotted lines: fittings explained in the text.

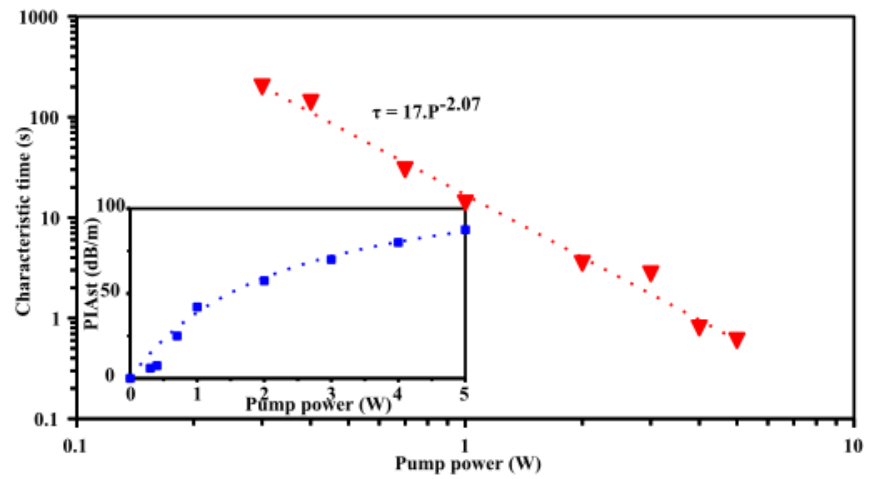

Fig. 11. Characteristic times and PIA steady state values (inset) for the $1300 \mathrm{ppm}$ cerium-doped sample as a function of pump power. Dot: experimental data, dotted lines: fitting in saturate linear for $P I A_{s t}$ and with a power law for the characteristic times.

$P I A_{s t}^{s a t}=125 \mathrm{~dB} / m$ and $A=0.45 W^{-1}$. The fitting is good except for some data at low pump power. Indeed, at low pump power the equilibrium level is low. Then, a longer length of fibre $(\sim 8 \mathrm{~cm})$ was required, and the equilibrium values were undervalued. In comparison with cerium-free samples, the $P I A_{s t}^{\text {sat }}$ value is significantly reduced by a factor of 22 , and the parameter $A$ is reduced by a factor of $\sim 2$. The values of characteristic time as a function of the pump power are fitted by a single power law, with an exponent of $\sim 2$. On the contrary to the case of $\mathrm{Ce}$-free samples (cf Fig. 6), there is no trend with an exponent of 5 or 6 at low pump power. So, this 


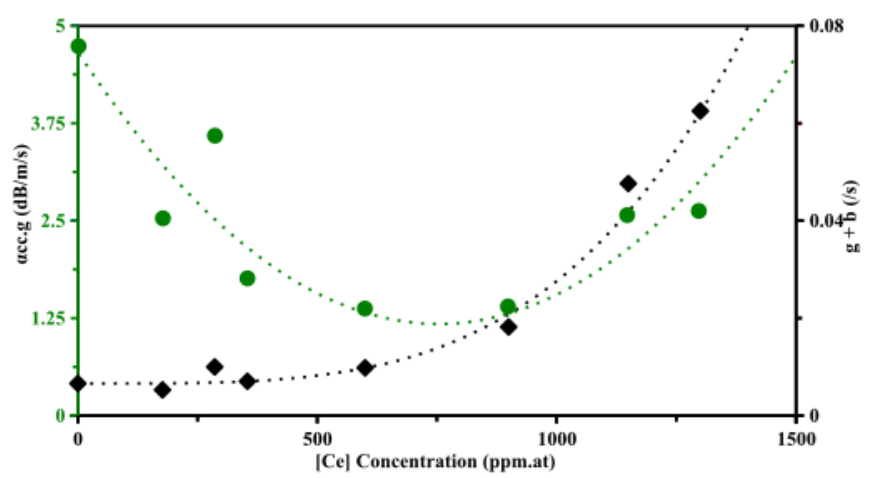

Fig. 12. $\alpha_{c} g$ et $g+b$ as a function of $C e$ concentration. Symbol: experimental values, dotted lines: fittings.

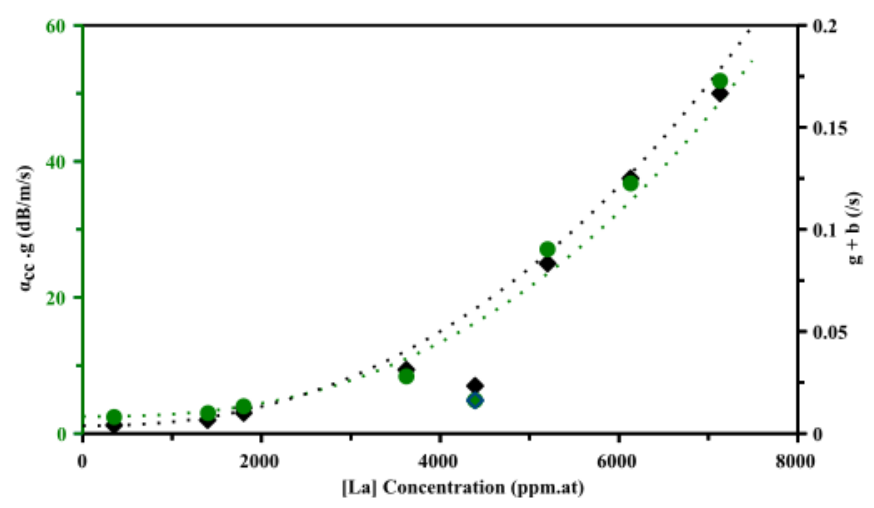

Fig. 13. $\alpha_{c c} g$ et $g+b$ as function of the lanthanum concentration. Symbol: experimental values, line: adjustments in power laws.

strongly suggests that the photo-darkening dynamics would be ruled by bleaching, namely the photo-bleaching by the pump.

The characteristic times and PIAst values are then interpreted. The $\alpha_{c c} . g$ and $g+b$ parameters as a function of Ce and La concentrations are shown in Figs. 12 and 13, respectively.

In the case of $\mathrm{Ce}$-doped samples, $\alpha_{c c} . \mathrm{g}$ parameter has a nonmonotonic behaviour. From 0 to $750 \mathrm{ppm}$ of cerium, this parameter decreases from 4.8 to $1.25 \mathrm{~dB} / \mathrm{m} / \mathrm{s}$ while it increases when cerium concentration is higher than $750 \mathrm{ppm}$. These measurements are fitted with a second order polynomial function and a satisfying match is found (green dotted curve in Fig. 12). The parameter $g+b$ is quite stationary at low $\mathrm{Ce}$ concentration, then it increases. These data are fitted with a power law (the exponent is 3.71) and a good match is also found (black dotted curve in Fig. 12). At low concentration of cerium, $g$ decreases and $g+b$ stays constant, meaning that $b$ increases. At higher concentration of cerium, $g$ and $g+b$ increase. Consequently it is impossible to determine the variation of $b$.

For La-doped samples, the value of $\alpha_{c c} . g$ increases by one order of magnitude, from 5 to $50 \mathrm{~dB} / \mathrm{m} / \mathrm{s}$ as the lanthanum concentration increases from 0 to $7000 \mathrm{ppm}$. For the same range of concentration, the parameter $g+b$ changes from 0.005 to $0.17 / s$. These data were fitted by two different power laws. The exponents are 2.5 and 2.3 for $\alpha_{c c} . g$ and $g+b$ curves, respectively. The difference between these two exponents may seem low but no simultaneous satisfying agreement is found for the four charts (Figs. 10 and 13) with equal exponents. As both $g$ and $g+b$ increase, it is not possible to discuss confidently on the variation of each parameter.

An inverse mathematical transformation is applied to derive the fitting of $P I A_{s t}$ and $\tau_{1 / e}$ data (dotted curves in Figs. 9 and 10). A good matching is found for all the data except for two concentrations of $\mathrm{Ce}(\sim 250 \mathrm{ppm})$. These two samples have different concentrations of $\mathrm{Tm}$ compared to the other samples of the series: $\mathrm{Tm}$ concentration is 240 and $350 \mathrm{ppm}$ in the ' $180 \mathrm{ppmCe}$ ' and ' $260 \mathrm{ppmCe}$ ' samples, respectively. As already indicated in Fig. 5, any change in $\mathrm{Tm}$ concentration strongly impacts the characteristic times and, to a less extent, $P I A_{s t}$ values.

5.3. Effect of cerium and lanthanum concentrations on the photodarkening after pumping with high probe power

The variations of PIA versus time for three concentrations of $\mathrm{Ce}$ and $L a$ are reported in Figs. 14 and 15, respectively. Before "Pump stop", the pump laser is on and its power is $1 \mathrm{~W}$. At "Pump stop", the pump laser is switched off and the probe power remains the same.

After the pump is turned off, the rare-earth ion ( $\mathrm{Ce}$ or $\mathrm{La}$ ) concentrations influence the recovery of the photo-darkening. The higher the rare-earth ions concentrations, the higher the recovery. One can note that at $t=3600 \mathrm{~s}$ (Fig. 14), the PIA absolute value increases suddenly for the sample without cerium. We assume that this increase is due to the vanishing of the green light emitted by $\mathrm{Tm}^{3+}$ under pumping.

Cerium-doped samples exhibit stronger photo-bleaching dynamics than the $L a$ ones. However, the bleaching is not complete, even after a long time. Such bleaching effects have been observed previously in cerium-doped fibre under UV excitation [31] and more recently in ytterbium doped fibre [32-34] and ytterbiumcerium co-doped fibre under pumping at $976 \mathrm{~nm}[35,36]$. But the role of cerium on these effects was not discussed and probe powers were not specified.

\subsection{Fluorescence lifetimes of the ${ }^{3} \mathrm{H}_{4}: \mathrm{Tm}^{3+}$-level}

Fluorescence lifetime measurements were performed on all samples series. The monitored emission issued from the ${ }^{3} \mathrm{H}_{4}$ level of $\mathrm{Tm}^{3+}$ is very sensitive to the phonon energy. For all measurements, the decay curves were non-exponentials. Then, we considered the $1 / e$ values for the lifetimes, reported in Fig. 16. For all these samples, the aluminum concentration remains constant around $\sim 8000 \mathrm{ppm}$. So, we assume that the variation of fluorescence lifetimes are only caused by rare-earth ion concentrations.

For Tm samples series, the fluorescence lifetime remains constant (about $19.5 \mu \mathrm{s}$ ) when the concentration of $\mathrm{Tm}$ varies between 160 and $600 \mathrm{ppm}$. Despite a quite high concentration of $\mathrm{Tm}$, no quenching was reported in these samples. Interestingly, $\mathrm{Ce}$ and $\mathrm{La}$ have opposite effect: $C e$ decreases the fluorescence lifetime $(-2.8 \mu \mathrm{s} / 1000 \mathrm{ppm})$ while $L a$ increases it $(+1.5 \mu \mathrm{s} / 1000 \mathrm{ppm})$.

The increase of the $\mathrm{Tm}^{3+}$ lifetime is discussed in the light of previous studies related to the effect of the local phonon energy on

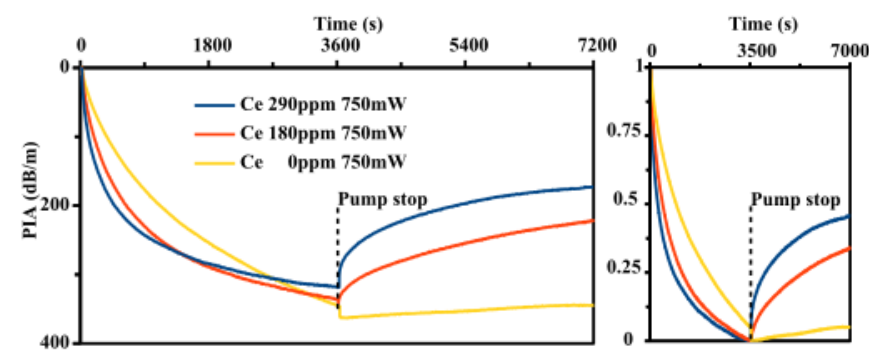

Fig. 14. Left: Time resolved PIA measurements for various $C e$ concentrations. Pump power before "Pump stop": $750 \mathrm{~mW}$ ( $0 \mathrm{~W}$ after "Pump stop"), probe power: $25 \mu W$. Right: same measurements with normalized PIA curves. 

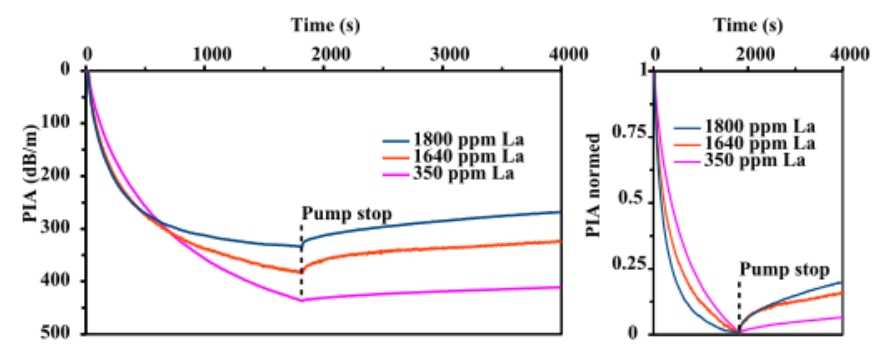

Fig. 15. Left: Time resolved $P I A$ measurements for various La concentrations. Pump power before "Pump stop": $750 \mathrm{~mW}$ (0 W after "Pump stop"), probe power: $25 \mu \mathrm{W}$. Right: same measurements with normalized PIA curves.

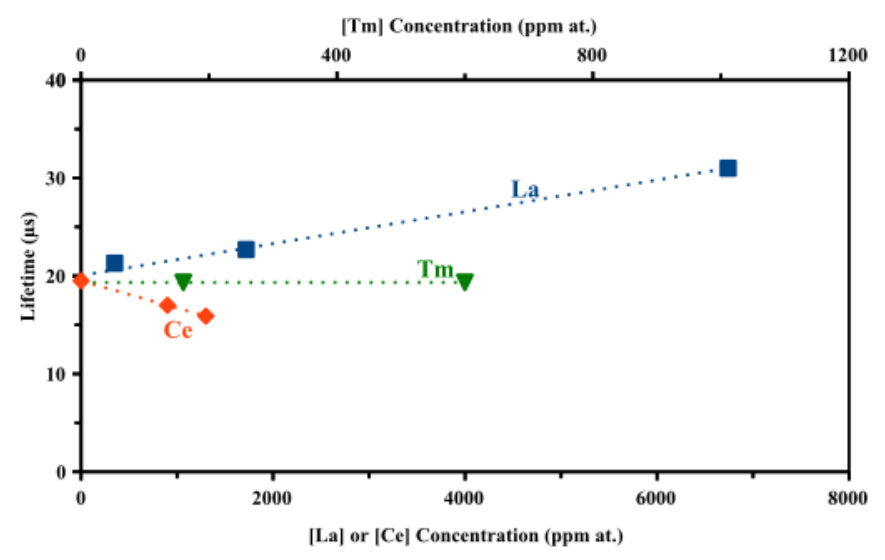

Fig. 16. Fluorescence lifetimes versus concentrations of $\mathrm{Tm}, \mathrm{La}$ and $\mathrm{Ce}$.

the ${ }^{3} \mathrm{H}_{4}$ level lifetime [11,12,37]. The improvement of the Tm-fluorescence lifetime can be interpreted in the frame of the change of its local phonon energy $\left(E_{p}\right)$ as previously reported for aluminium [11]. Indeed, a higher content of $L a$ in the Tm environment may decrease the local phonon energy $\left(E_{p}\left(\mathrm{La}_{2} \mathrm{O}_{3}\right)=400 \mathrm{~cm}^{-1}\right.$, $\left.E_{p}\left(\mathrm{Al}_{2} \mathrm{O}_{3}\right)=870 \mathrm{~cm}^{-1}, E_{p}\left(\mathrm{SiO}_{2}\right)=1100 \mathrm{~cm}^{-1}\right)$, then enhance the population in the ${ }^{3} \mathrm{H}_{4}$ level, as describe in Ref. [37]. Due to the lower phonon energy of $\mathrm{La}_{2} \mathrm{O}_{3}$ compared to that of $\mathrm{Al}_{2} \mathrm{O}_{3}$, $\mathrm{La}$ would be more efficient to increase the $\mathrm{Tm}$-fluorescence lifetime. The same mechanism would occur with $\mathrm{Ce}$ but with this ion the lifetime decreases. The decrease of the lifetimes has been reported previously for the ${ }^{4} I_{\frac{11}{2}}$ level of erbium in tellurium and sulfur based glasses [38-40]. It was explained by an energy transfer mechanism between erbium and cerium ions. As the energy difference between the ${ }^{3} \mathrm{H}_{4}$ and the ${ }^{3} \mathrm{H}_{5}$ energy levels of $\mathrm{Tm}^{3+}\left(\sim 4000 \mathrm{~cm}^{-1}\right)$ and between the ${ }^{4} I_{\frac{11}{2}}$ and the ${ }^{4} I_{\frac{13}{2}}$ energy levels of $\mathrm{Er}^{3+}\left(\sim 3600 \mathrm{~cm}^{-1}\right)$ are very close, we hypothesize this energy transfer:

$\mathrm{Tm}:{ }^{3} \mathrm{H}_{4} ; 2 \times \mathrm{Ce}:{ }^{2} \mathrm{~F}_{\frac{7}{2}} \rightarrow \mathrm{Tm}:{ }^{3} \mathrm{H}_{5} ; 2 \times \mathrm{Ce}:{ }^{2} \mathrm{~F}_{\frac{5}{2}}$

involving one $\mathrm{Tm}^{3+}$ ion and two $\mathrm{Ce}^{3+}$ ions (the energy difference between the ${ }^{2} F_{5 / 2}$ and ${ }^{2} F_{7 / 2}$ levels of $C e^{3+}$ is about $2000 \mathrm{~cm}^{-1}$ ). Following this energy transfer, both cerium ions quickly de-excite by emitting two phonons each, and the thulium ion falls into the ${ }^{3} \mathrm{~F}_{4}$ level.

\section{Discussions}

In Tm-doped fibres, the photo-induced attenuation is due to the balance between the generation and the bleaching mechanisms.
The generation of color-centres is caused by the ability of $\mathrm{Tm}^{3+}$ ions to emit UV photons through up-conversion mechanisms when it is pumped at $1.07 \mu \mathrm{m}$. This UV photon ionizes a precursor and, depending on the centre, an electron is released in the conduction band and can be trapped by a $\mathrm{Tm}^{3+}$ ion to form a $\mathrm{Tm}^{2+}$ ion, or a hole is released in the valence band and it can be trapped to form, for example, an $\mathrm{AlOHC}$ centre. These color-centres can be bleached by absorbing two pump photons or one probe photon. For example, $\mathrm{Tm}^{2+}$ ion recovers its initial trivalent state. By adding $\mathrm{Ce}$ or $\mathrm{La}$, both $P I A_{s t}$ and characteristic time values decrease. This indicates that these ions would act favourably on the photo-bleaching mechanism (see Table 2).

Cerium addition brings an almost total solution to darkening problem. Indeed, the equilibrium levels drop drastically. An addition of $1300 \mathrm{ppm} \mathrm{Ce}$ induces a drop of $95 \%$ of degradation level. Cerium ions can decrease $g$ for three reasons:

- as fluorescence lifetime decreases (Fig. 16), there are less $\mathrm{Tm}^{3+}$ ions in the higher energy levels, then less UV photons are emitted, this can barely affect the generation.

- cerium is known to be present also in its tetravalent state in silica [15,41]. Ce $e^{4+}$ can absorb UV photon (charge transfer band) emitted by $\mathrm{Tm}^{3+}$ ions to form $\mathrm{Ce}^{3+}$ ion which is stable over several months $[42,43]$. These two valence states of cerium are transparent in the visible [44]. Hence, this phenomenon is in competition with the generation of color-centre and therefore reduces the photo-darkening.

- cerium ion has two valence states, it can trap electron $\left(\mathrm{Ce}^{4+} \rightarrow \mathrm{Ce}^{3+}\right)$ and hole $\left(\mathrm{Ce}^{3+} \rightarrow \mathrm{C} e^{4+}\right)$ to the detriment of the formation of color-centres.

Moreover, when $\mathrm{RE}^{3+}$ ion is added into alumino-silicate glasses, it acts as a charge compensator if $\left[\mathrm{RE}_{2} \mathrm{O}_{3}\right] \leq \frac{\left[\mathrm{Al}_{2} \mathrm{O}_{3}\right]}{3}$ (or $\left[\mathrm{REO}_{2}\right] \leq \frac{\left[\mathrm{Al}_{2} \mathrm{O}_{3}\right]}{4}$ for $\mathrm{Ce}^{4+}$ ) [45]. As a consequence, $\mathrm{RE}$ is located preferentially close to the tetra-coordinated $A l^{I V}$ species. $\mathrm{Ce}$ and $\mathrm{Tm}$ compete to be located close to $A l^{N}$ species. Therefore, Ce tends to reduce the probability of $\mathrm{Tm}$-cluster formation and hence the emission of UV photons. When cerium concentration is above the threshold of the charge compensator effect, it acts as network modifier and depolymerizes the silica network. This depolymerization may lead to the formation of new precursors defects [46]. This may explain why $g$ increases at higher content of cerium.

The bleaching mechanism is related to the ionization of colorcentres. In this case, an electron is released in the conduction band. The presence of cerium ions offers a new opportunity for this electron to be trapped by $\mathrm{Ce}^{4+}$, to the detriment of $\mathrm{Tm}^{3+}$ ions. The same stands for the ionization of the $\mathrm{AlOHC}$ centre as the hole released in the valence band can be trapped by $\mathrm{Ce}^{3+}$ ions.

On the contrary to cerium ions, the addition of lanthanum tends to increase the fluorescence lifetime which would be a detrimental effect on the photo-darkening. Indeed, this would promote the population of $\mathrm{Tm}^{3+}$ in the high energy levels, then the emission of UV photon and the generation of color-centres. However, lanthanum ions allow to reduce photo-darkening. Compared to cerium, lanthanum ion does not absorb UV photon and has only one stable valence state, $\mathrm{La}^{3+}$. The divalent and tetravalent states are not stable in silica $[27,28]$. An electron has the possibility to recombine on ionized precursor, $\mathrm{Tm}^{3+}$ and $\mathrm{La}^{3+}$. If it recombines on $\mathrm{La}^{3+}$, the new valence is not stable and the electron will move away until reaching a stable recombination. Hence, lanthanum addition decreases the probability of recombination on a thulium, and keeps constant the probability of recombination of an ionized precursor. 
Therefore, the addition of lanthanum would lead to the increase of the parameter $b$ because it would increase the probability for an electron to return to an ionized precursor. Moreover, as already discussed in the case of cerium ions, at low content of $\mathrm{La}$, this ion could limit the formation of $\mathrm{Tm}$-clusters [47], while at high content, this ion would also act as a network modifier, increasing the numbers of precursor defect [46].

\section{Conclusion}

Three sets of samples were investigated, all doped with thulium and aluminium and co-doped with cerium or lanthanum. In each series, the impact on photo-darkening of rare-earth ions was studied. The photo-darkening was characterized by its steady state value $\left(P I A_{s t}\right)$ and also its characteristic time. Thanks to a rate equation model, these parameters were related to the generation and sum of generation and bleaching rates. While PIAst increases with the $\mathrm{Tm}$ concentration, the addition of $\mathrm{Ce}$ or $\mathrm{La}$ allows the PIA $A_{s t}$ and the characteristic time to reduce. Most importantly, we reveal that the main impact of cerium and lanthanum on photo-darkening is due to their effect on the bleaching mechanisms. This can be explained by the ability of cerium ions to trap holes or electrons. In the case of lanthanum co-doping, the probability for a charge to return to an ionized precursor would be increased by the instability of the divalent and tetravalent states of lanthanum.

Cerium and lanthanum reduce the steady state degradation because they have a strong impact on photo-bleaching. This an increment on the comprehension of darkening process. These results could be transposed to other systems like $Y b$ - or Er-doped fibres in order to enhance actual devices and create new devices and new applications.

\section{Funding}

Université Nice Sophia Antipolis, Centre National de la Recherche Scientifique, Agence Nationale de la Recherche (ANR-14-CE070016-01, Nice-DREAM).

\section{Acknowledgements}

All of the authors want to thank S. Trzesien and M. Ude (IN $\Phi N I$, Nice, France) for the fabrication of the samples and M. Fialin (IPGP Camparis, Paris, France) for EPMA measurements.

\section{References}

[1] D. Richardson, J. Nilsson, W. Clarkson, High power fiber lasers: current status and future perspectives [invited], JOSA B 27 (11) (2010) B63-B92.

[2] I. Manek-H, J. Boullet, T. Cardinal, F. Guillen, S. Ermeneux, M. Podgorski, R.B. Doua, F. Salin, Photodarkening and photobleaching of an ytterbium-doped silica double-clad LMA fiber, Opt. Express 15 (4) (2007) 1606-1611.

[3] H.-J. Otto, N. Modsching, C. Jauregui, J. Limpert, A. Tünnermann, Impact of photodarkening on the mode instability threshold, Opt. Express 23 (12) (2015) 15265-15277.

[4] J. Lægsgaard, Optimizing $\mathrm{Yb}$ concentration of fiber amplifiers in the presence of transverse modal instabilities and photodarkening, Appl. Opt. 55 (8) (2016) 1966-1970.

[5] M. Laurila, M.M. Jørgensen, K.R. Hansen, T.T. Alkeskjold, J. Broeng, J. Lægsgaard, Distributed mode filtering rod fiber amplifier delivering $292 \mathrm{~W}$ with improved mode stability, Opt. Express 20 (5) (2012) 5742-5753.

[6] M.M. Johansen, M. Laurila, M.D. Maack, D. Noordegraaf, C. Jakobsen, T.T. Alkeskjold, J. Lægsgaard, Frequency resolved transverse mode instability in rod fiber amplifiers, Opt. Express 21 (19) (2013) 21847-21856.

[7] D. Hanna, I. Jauncey, R. Percival, I. Perry, R. Smart, P. Suni, J. Townsend, A. Tropper, Continuous-wave oscillation of a monomode thulium-doped fibre laser, Electron. Lett. 24 (19) (1988) 1222-1223.

[8] X. Zhu, N. Peyghambarian, High-power ZBLAN glass fiber lasers: review and prospect, Adv. Optoelectron. (2010), http://dx.doi.org/10.1155/2010/501956. Article ID 501956, 23 pages.

[9] J. Van Dijk, M. Schuurmans, On the nonradiative and radiative decay rates and a modified exponential energy gap law for $4 \mathrm{f}-4 \mathrm{f}$ transitions in rare-earth ions, J. Chem. Phys. 78 (9) (1983) 5317-5323.

[10] M. Broer, D. Krol, D. DiGiovanni, Highly nonlinear near-resonant photodarkening in a thulium-doped aluminosilicate glass fiber, Opt. Lett. 18 (10) (1993) 799-801.

[11] B. Faure, W. Blanc, B. Dussardier, G. Monnom, Improvement of the $\mathrm{Tm}^{3+}:{ }^{3} \mathrm{H}_{4}$ level lifetime in silica optical fibers by lowering the local phonon energy, J. Non-Cryst. Solids 353 (29) (2007) 2767-2773.

[12] W. Blanc, T.L. Sebastian, B. Dussardier, C. Michel, B. Faure, M. Ude, G. Monnom, Thulium environment in a silica doped optical fibre, J. Non-Cryst. Solids 354 (2) (2008) 435-439.

[13] S. Jetschke, S. Unger, A. Schwuchow, M. Leich, J. Fiebrandt, M. Jäger, J. Kirchhof, Evidence of Tm impact in low-photodarkening Yb-doped fibers, Opt. Express 21 (6) (2013) 7590-7598.

[14] M. Engholm, L. Norin, Preventing photodarkening in ytterbium-doped high power fiber lasers; correlation to the uv-transparency of the core glass, Opt. Express 16 (2) (2008) 1260-1268.

[15] M. Engholm, P. Jelger, F. Laurell, L. Norin, Improved photodarkening resistivity in ytterbium-doped fiber lasers by cerium codoping, Opt. Lett. 34 (8) (2009) $1285-1287$.

[16] D. Litzkendorf, S. Grimm, K. Schuster, J. Kobelke, A. Schwuchow, A. Ludwig, J. Kirchhof, M. Leich, S. Jetschke, J. Dellith, Study of lanthanum aluminum silicate glasses for passive and active optical fibers, Int. J. Appl. Glass Sci. 3 (4) (2012) 321-331.

[17] S. Jetschke, S. Unger, U. Röpke, J. Kirchhof, Photodarkening in Yb doped fibers: experimental evidence of equilibrium states depending on the pump power, Opt. Express 15 (22) (2007) 14838-14843.

[18] J.-F. Lupi, M. Vermillac, W. Blanc, F. Mady, M. Benabdesselam, B. Dussardier, D.R. Neuville, Steady photodarkening of thulium alumino-silicate fibers pumped at $1.07 \mu \mathrm{m}$ : quantitative effect of lanthanum, cerium, and thulium, Opt. Lett. 41 (12) (2016) 2771-2774.

[19] J. MacChesney, P. O'connor, H. Presby, A new technique for the preparation of low-loss and graded-index optical fibers, Proc. IEEE 62 (9) (1974) 1280-1281.

[20] J. Townsend, S. Poole, D.N. Payne, Solution-doping technique for fabrication of rare-earth-doped optical fibres, Electron. Lett. 23 (7) (1987) 329-331.

[21] S. Jetschke, U. Röpke, Power-law dependence of the photodarkening rate constant on the inversion in Yb doped fibers, Opt. Lett. 34 (1) (2009) 109-111.

[22] R. Paschotta, P. Barber, A. Tropper, D. Hanna, Characterization and modeling of thulium: ZBLAN blue upconversion fiber lasers, JOSA B 14 (5) (1997) 1213-1218.

[23] L. Skuja, Optical properties of defects in silica, in: Defects in $\mathrm{SiO}_{2}$ and Related Dielectrics: Science and Technology, Springer, 2000, pp. 73-116.

[24] D.L. Griscom, Defect structure of glasses: some outstanding questions in regard to vitreous silica, J. Non-Cryst. Solids 73 (1) (1985) 51-77.

[25] N. Koumvakalis, Defects in crystalline $\mathrm{SiO}_{2}$ : optical absorption of the aluminum-associated hole center, J. Appl. Phys. 51 (10) (1980) 5528-5532.

[26] Z.J. Kiss, Energy levels of divalent thulium in $\mathrm{C} a F_{2}$, Phys. Rev. 127 (3) (1962) 718.

[27] P. Dorenbos, Systematic behaviour in trivalent lanthanide charge transfer energies, J. Phys. Condens. Matter 15 (49) (2003) 8417.

[28] P. Dorenbos, Anomalous luminescence of $\mathrm{Eu}^{2+}$ and $\mathrm{Yb}^{2+}$ in inorganic compounds, J. Phys. Condens. Matter 15 (17) (2003) 2645.

[29] Y.H. Kim, U.-C. Paek, W.-T. Han, J. Heo, Absorption and emission properties of $\mathrm{Tm}^{2+}$ ions in germanosilicate glass fibers, Opt. express 11 (21) (2003) 2672-2678.

[30] G.H. Dieke, H. Crosswhite, The spectra of the doubly and triply ionized rare earths, Appl. Opt. 2 (7) (1963) 675-686.

[31] M. Broer, R. Cone, J.R. Simpson, Ultraviolet-induced distributed-feedback gratings in $\mathrm{Ce}^{3+}$-doped silica optical fibers, Opt. Lett. 16 (18) (1991) 1391-1393.

[32] A. Jolly, C. Vinçont, J. Boullet, Photo-darkening kinetics in a high-power YDFA versus CW or short-pulse seed conditions, in: Proc. of SPIE, vol. 10083, 2017, pp. $100831 \mathrm{~T}-1$.

[33] R. Piccoli, H. Gebavi, L. Lablonde, B. Cadier, T. Robin, A. Monteville, O. Le Goffic, D. Landais, D. Mechin, D. Milanese, T. Brand, S. Taccheo, Evidence of photodarkening mitigation in $\mathrm{Yb}$-doped fiber lasers by low power $405 \mathrm{~nm}$ radiation, IEEE Photonics Technol. Lett. 26 (1) (2014) 50-53.

[34] R. Piccoli, T. Robin, T. Brand, U. Klotzbach, S. Taccheo, Effective photodarkening suppression in $\mathrm{Yb}$-doped fiber lasers by visible light injection, Opt. Express 22 (7) (2014) 7638-7643.

[35] S. Jetschke, S. Unger, A. Schwuchow, M. Leich, M. Jäger, Role of ce in Yb/Al laser fibers: prevention of photodarkening and thermal effects, Opt. Express 24 (12) (2016) 13009-13022.

[36] N. Zhao, Y. Wang, J. Li, C. Liu, J. Peng, H. Li, N. Dai, L. Yang, J. Li, Investigation of cerium influence on photo-darkening and photo-bleaching in Yb-doped fibers, Appl. Phys. A 122 (2) (2016) 1-5.

[37] M. Vermillac, H. Fneich, J.-F. Lupi, J.-B. Tissot, C. Kucera, P. Vennéguès, A. Mehdi, D. R. Neuville, J. Ballato, W. Blanc, Use of thulium-doped LaF nanoparticles to lower the phonon energy of the thulium's environment in silicabased optical fibres, Opt. Mater.

[38] Y.G. Choi, K.H. Kim, S.H. Park, J. Heo, Comparative study of energy transfers from $\mathrm{Er}^{3+}$ to $\mathrm{Ce}^{3+}$ in tellurite and sulfide glasses under $980 \mathrm{~nm}$ excitation, J. Appl. Phys. 88 (7) (2000) 3832-3839.

[39] J. Yang, L Zhang, L. Wen, S. Dai, L. Hu, Z Jiang, Comparative investigation on energy transfer mechanisms between $\mathrm{Er}^{3+}$ and $\mathrm{Ce}^{3+}\left(\mathrm{Eu}^{3+}, \mathrm{Tb}^{3+}\right)$ in tellurite 
glasses, Chem. Phys. Lett. 384 (4) (2004) 295-298.

[40] S. Shen, B. Richards, A. Jha, Enhancement in pump inversion efficiency at 980 $\mathrm{nm}$ in $\mathrm{Er}^{3+}, \mathrm{Er}^{3+} / \mathrm{Eu}^{3+}$ and $\mathrm{Er}^{3+} / \mathrm{Ce}^{3+}$ doped tellurite glass fibers, Opt. Express 14 (12) (2006) 5050-5054.

[41] S. Unger, A. Schwuchow, S. Jetschke, S. Grimm, A. Scheffel, J. Kirchhof, Optical properties of cerium-codoped high power laser fibers, SPIE OPTO 8621 (2013) 16.

[42] M. Raukas, S. Basun, W. Van Schaik, W. Yen, U. Happek, Luminescence efficiency of cerium doped insulators: the role of electron transfer processes, Appl. Phys. Lett. 69 (22) (1996) 3300-3302.

[43] L. Dong, P. Wells, D. Hand, D.N. Payne, Photosensitivity in $\mathrm{Ce}^{3+}$-doped optical fibers, JOSA B 10 (1) (1993) 89-93.

[44] M. Fasoli, A. Vedda, A. Lauria, F. Moretti, E. Rizzelli, N. Chiodini, F. Meinardi,
M. Nikl, Effect of reducing sintering atmosphere on Ce-doped sol-gel silica glasses, J. Non-Cryst. Solids 355 (18) (2009) 1140-1144.

[45] P. Florian, N. Sadiki, D. Massiot, J. Coutures, ${ }^{27}$ Al NMR study of the structure of lanthanum-and yttrium-based aluminosilicate glasses and melts, J. Phys Chem. B 111 (33) (2007) 9747-9757.

[46] C. Karras, D. Litzkendorf, S. Grimm, K. Schuster, W. Paa, H. Stafast, Nonlinea refractive index study on $\mathrm{La}_{2} \mathrm{O}_{3}-\mathrm{Al}_{2} \mathrm{O}_{3}-\mathrm{SiO}_{2}$ glasses, Opt. Mater. Express 4 (10) (2014) 2066-2077.

47] J.L. Philipsen, J. Broeng, A. Bjarklev, S. Helmfrid, D, Bremberg, B. Jaskorzynska, B. Palsdonir, Observation of strongly nonquadratic homogeneous upconversion in $\mathrm{Er}^{3+}$-doped silica fibers and reevaluation of the degree of clustering Quantum Electron. IEEE J. 35 (11) (1999) 1741-1749. 